\title{
Inferior dermoglandular flap for autologous breast remodeling following explantation of breast implants in ptotic breasts: a case report and literature search
}

\author{
Umar Daraz Khan \\ Reshape Clinic, West Malling, ME19 6QR, Kent, UK.
}

Address for correspondence: Mr. Umar Daraz Khan, Reshape Clinic, Reshape House, 2-4 High Street, West Malling, ME19 6QR, Kent, UK. E-mail: mrumarkhan@aol.com

\begin{abstract}
Explantation following aesthetic mammoplasty without implant replacement is quite uncommon and often leaves the patient worse off than prior to mammoplasty. A case is presented here in which patient's own tissue was used as an inferior dermoglandular flap for autologous breast remodeling. Inferior dermal flap has been described for breast reconstruction and simultaneous augmentation mammoplasty with mastopexy for prosthesis cover in the lower pole of the breast, but its use following explantation without implant replacement has not been described for breast remodeling and volume conservation.
\end{abstract}

Key words:

Autologous breast augmentation, bostwick flap, breast remodeling, explantation, revision augmentation mammoplasty

\section{INTRODUCTION}

Augmentation mammoplasty is a commonly performed procedure. The procedure helps to enhance breast cup size by filling out an empty breast skin envelope. Following implantation skin gets further stretched and thinned down due to the pressure exerted by implants in a tight space. Explantation alone following augmentation mammoplasty is not very common. Removal of prosthesis results in loose, empty and often a ptotic breast skin envelope leaving patient worse off than prior to the procedure. Ptosis and skin excess may necessitate mastopexy that may further reduce breast volume resulting in loss of female proportion and body silhouette. This anticipated loss of feminine curves and accompanied

\begin{tabular}{|l|l|}
\hline \multicolumn{2}{|c|}{ Access this article online } \\
\hline Quick Response Code: & Website: \\
\hline & www.parjournal.net \\
\hline & \\
\hline
\end{tabular}

loss of confidence is the reason that the explantation alone following aesthetic augmentation mammoplasty is not commonly performed. Breast remodeling in these patients is often challenging and extremely important and should be offered by a surgeon as an option, where possible. A case report is presented where autologous breast tissue is used in the form de-epithelialized inferior dermoglandular flap for volume conservation and breast remodeling along with simultaneous mastopexy using Wise pattern markings following bilateral explantation of breast implants.

\section{CASE REPORT}

A 42-year-old mother of 4 children and a care assistant presented with neck and back ache. She had augmentation mammoplasty 5 years ago using $450 \mathrm{~mL}$ Eurosilicone anatomical implants. She considered her breasts too large and was concerned with resultant neck and backache. She requested removal of implants without replacement. She requested reduction of her breast cup size down from E to $\mathrm{C}$.

Examination showed a cup size of $34 \mathrm{E}$ with jugular notch to nipple areola complex distance of $26 \mathrm{~cm}$. Her nipple to 
inframammary crease distance, was $11 \mathrm{~cm}$ bilaterally with a bilateral sliding ptosis of the skin envelope.

Preoperative discussion primarily centered on the size of her breast and breast esthetics following explantation alone. She was informed that her breasts were likely to look very saggy if explantation alone was performed and if a simultaneous mastopexy was carried out, especially using a Wise Pattern markings, resultant tissue excision would reduce her breast to a small B cup at the most. Autologous breast remodeling was discussed either using fat transfer as a secondary procedure or using de-epithelialized inferior dermoglandular flap as volume conservation and remodeling in the same setting. She showed her interest in the later procedure. The procedure was planned under general anesthetic and as a day case.

\section{Markings and technique}

Patient was marked in standing position. Neo nipple areolar complex (NAC) was marked at $21 \mathrm{~cm}$ using infra-mammary crease as a reference [Figure 1]. Wise pattern markings were used for skin reduction with a medially based flap. A transversely oriented skin area, to be de-zepithelialized, was marked and cross-hatched below $7 \mathrm{~cm}$ vertical limbs of the markings [Figure 2]. Procedure was done under

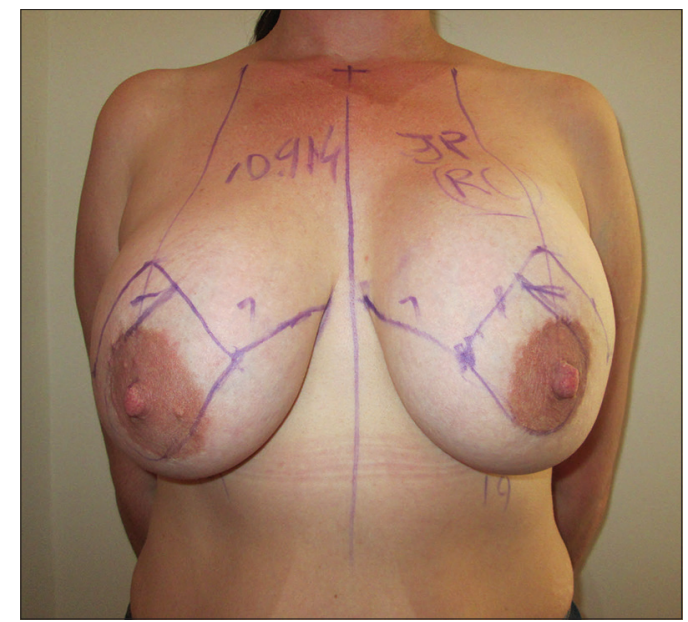

Figure 1: Patient showing preoperative wise pattern markings with medially based flap in standing position

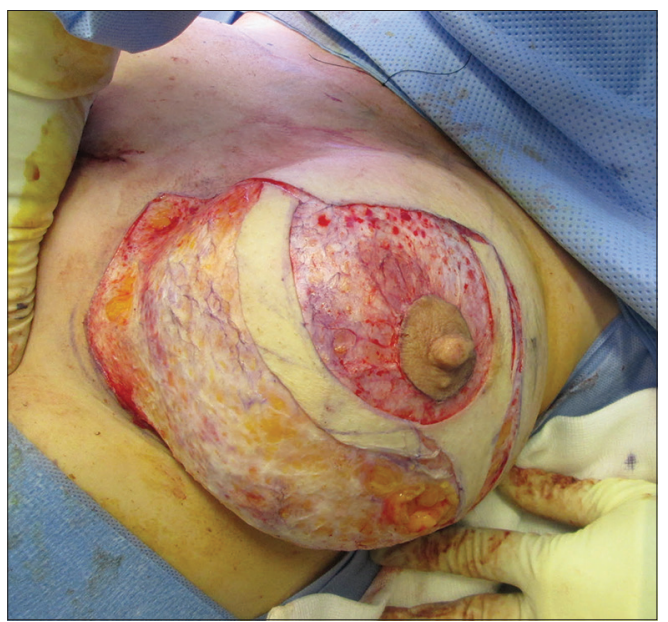

Figure 3: Left breast showing inferior dermoglandular flap and medially based nipple areolar complex flap de-epithelialized general anesthesia with the patient in supine position and arms abducted $<90^{\circ}$. Patient received a single dose of Cephalosporin intraoperatively. Cross-hatched area and medially based flap was de-epithelialized leaving $4.5 \mathrm{~cm}$ Neo NAC. Intervening tissue between the markings and de-epithelialized area was excised (right $87 \mathrm{gm}$ and left $119 \mathrm{gm}$ ) [Figure 3]. Both implants were removed, and both showed malorientation, fold flaw failures with a rupture on the right side [Figure 4]. De-epithelialized inferior dermoglandular flap was pulled up and stitched to pectoralis major, without tension and using 2-0 vicryl sutures [Figure 5]. Hemostasis was performed, and skin closure done using 3-0 vicryl and 4-0 monocryl and 4-0 monocryl was used suture to NAC. No drains were used, and patient was discharged on the same day. The patient was followed one and 3 weeks postoperatively, she had no neck or backache, her bra cup size was measured $34 \mathrm{C}$ and was extremely pleased with the results [Figures 6-8].

\section{DISCUSSION}

Augmentation mammoplasty is one of the most

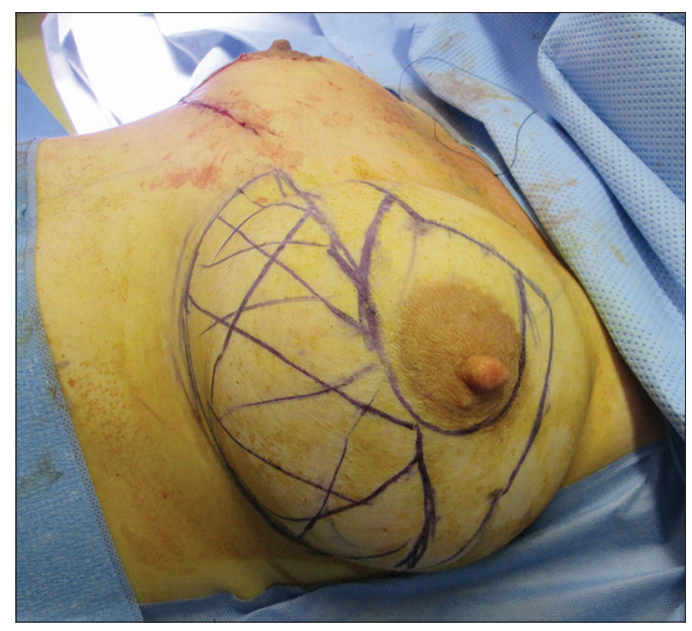

Figure 2: Patient in supine position showing markings of left breast inferior dermoglandular flap as cross-hatched lines. Right breast showing an on table completed procedure

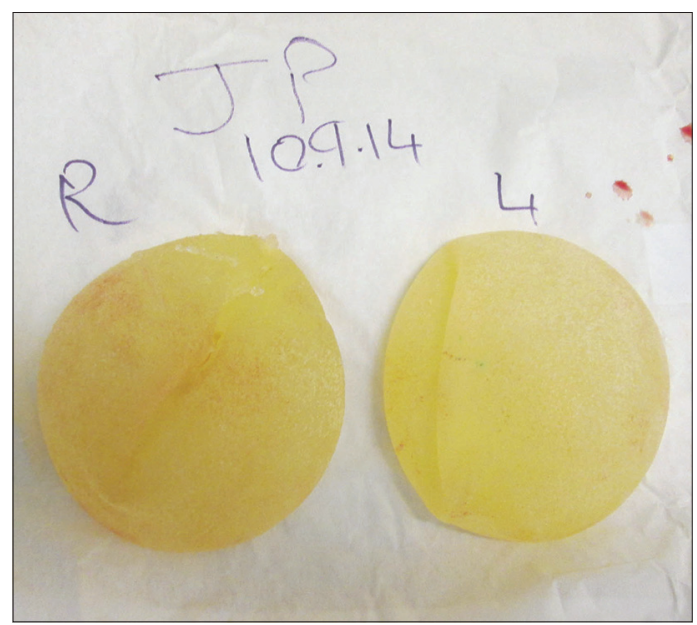

Figure 4: Picture showing explanted form stable anatomical implants with fold flaw failure. Right implant showing rupture at its superior pole 


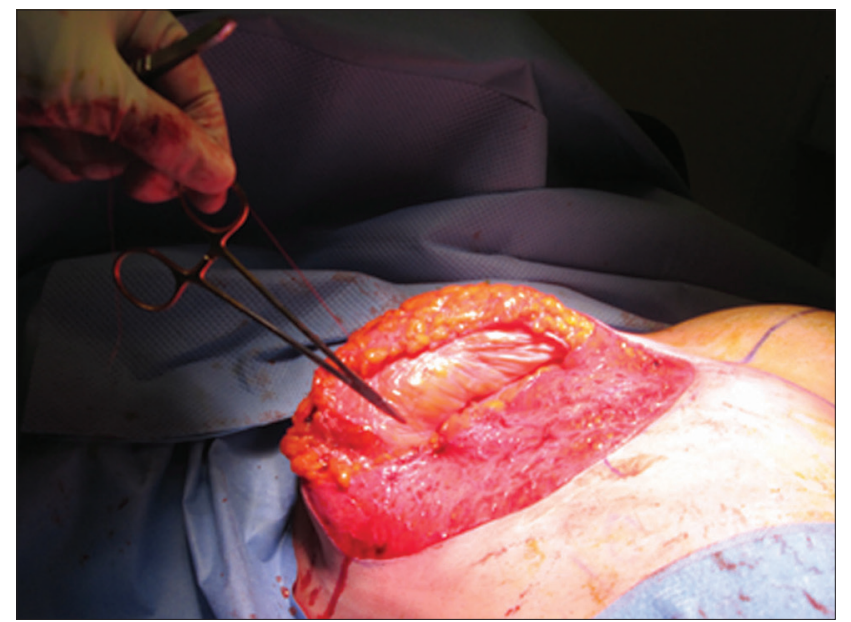

Figure 5: Picture showing right de-epithelialized inferior dermoglandular flap sutured to pectoralis major muscle

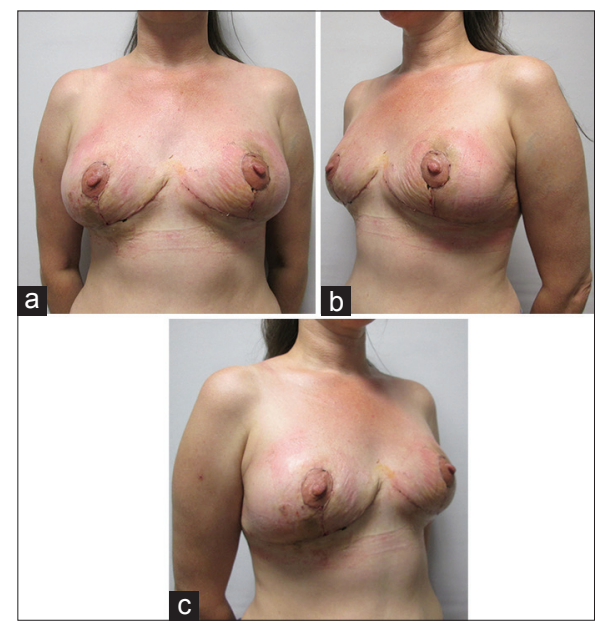

Figure 7: (a-c) Postoperative pictures showing results after 2 weeks following explantation and inferior dermoglandular de-epithelialized flap

commonly performed procedure by plastic and aesthetic surgeons today. Implant related mammoplasties for both primary and revision mammoplasties is considered a safe procedure with a high satisfaction rate and is due to the information available on the product, premarket surveys, enhanced implant safety and regular quality checks in place. ${ }^{[1]}$ It is not surprising that in 2012 alone 330,631 implant related mammoplasties were performed in USA. ${ }^{[2]}$ On the other hand, breast implant explantation without implant replacement following primary augmentation mammoplasty is very uncommon, the prevalence of the procedure or its incidence is lacking in the literature. In author's own experience, only three patients have requested explantation without breast implant replacement after performing over 4,000 implant related cosmetic mammoplasties. The rarity of the procedure makes it difficult to compile the effects on the patient or record the management of the loss of volume or resultant deformity. Explantation of breast prosthesis results in empty stretched and thinner skin envelope that is often accompanied with breast ptosis. The inferior de-epithelialized dermoglandular flap has been described for breast reconstruction with an aim to cover the prosthesis in the lower part of the breast.

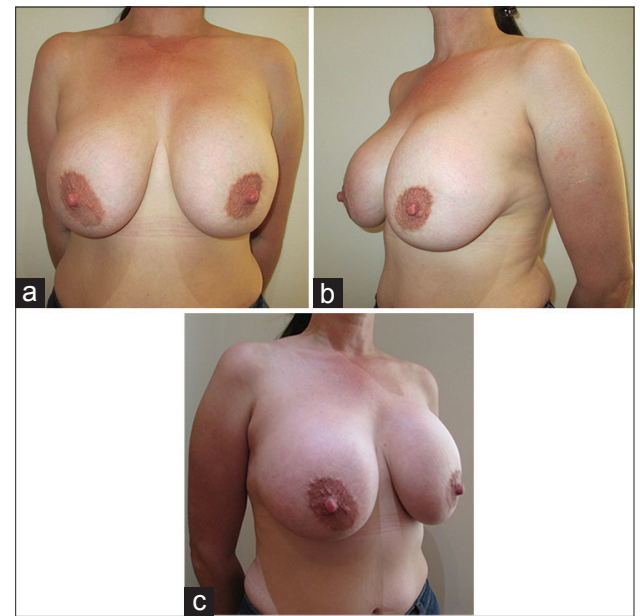

Figure 6: (a-c) Preoperative pictures of the patient before explantation

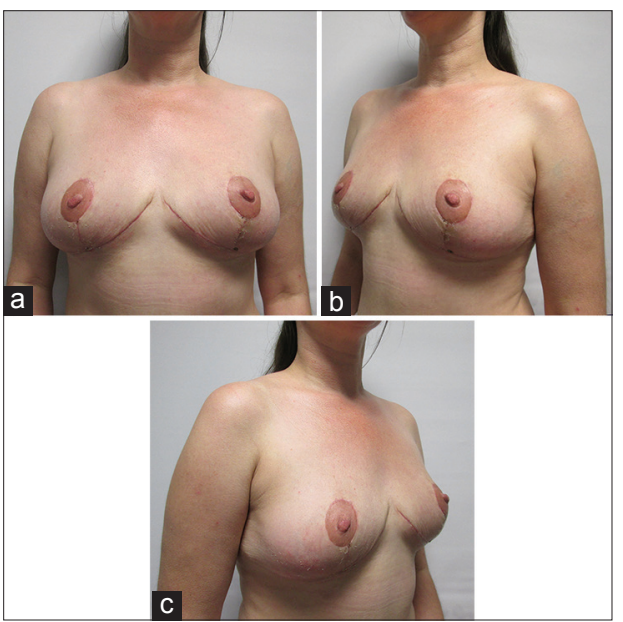

Figure 8: (a-c) Postoperative pictures showing results after 6 weeks following explantation and inferior dermoglandular de-epithelialized flap

The de-epithelialized flap maximizes implant coverage adding an extra layer of autologous tissue to minimize its extrusion..$^{[3-4]}$ The inferior dermoglandular flap has also been described when simultaneous augmentation mammoplasty is performed with mastopexy. ${ }^{[5]}$ Volume enhancement using autologous fat transfer is safe and commonly performed today for cosmetic as well as reconstructive procedures since the publication of the article by Coleman. ${ }^{[6]}$ However, in cases following explantation of prosthesis, the patients are left with quite large empty space with a thin breast skin envelope that can make the autologous fat transfer not an easy option. Volume restoration and aesthetic appearance following explantation can be even more challenging if there is an associated ptosis. However, if a patient presents with a markedly ptotic breast, the use of the excess skin can be materialized. In these cases, wise pattern mastopexy can be performed with the use of an inferior dermoglandular flap. This de-epithelialize flap conserves breast volume and helps to remodel the breast in this group of selected cases. The procedure can also be staged where explantation can be performed initially followed by mastopexy at least 3 months later to adjust any recoil of the breast. Vertical scar mastopexy can be a possible option to conserve breast tissue, but 
these markings for mastopexy may not be able to give adequate fullness or projection with a risk of bottoming down of the breast, especially when these patients presents with significant ptosis of breasts, excessive jugular notch to NAC or nipple to inframammary crease measurements. ${ }^{[7]}$ In recently described Four Flaps augmentation mastopexy, limited use of the width of the transverse inferior dermoglandular flap is recommended to avoid boxy appearance. ${ }^{[5]}$ In current case report, author has made use of the full transverse width for the de-epithelialized flap in order to maximize the autologous volume conservation as well as better breast projection and without any compromise to the aesthetic outcome. Ladizinsky et al. ${ }^{[8]}$ have modified the bostwick flap in their article suggesting full thickness incision in the medial and lateral inferior borders of the autoderm flap to optimize the implant coverage, limiting the medial and lateral transverse incisions and making vertical component short and narrow to minimize vascular compromise to breast envelope following subcutaneous mastectomy. No such measures are required in the use of inferior dermoglandular flap for autologous breast remodeling following explantation. The current case report is a useful technique that is aimed to conserve maximum possible autologous breast tissue and to minimize the physical and psychological morbidity associated following explantation in these patients.

In conclusion, wise pattern markings with a medially based NAC flap for mastopexy and its combination with inferior dermoglandular flap is a good option for breast remodeling and autologous breast volume conservation in patients requesting for explantation and presenting with breast ptosis.

\section{REFERENCES}

I. Khan UD. Combining muscle splitting biplane with multilayer capsuloraphy for the correction of bottoming down following subglandular augmentation. Eur J Plast Surg 2010;33:259-69.

2. The American Society for Aesthetic Plastic Surgery. Cosmetic Surgery National Data Bank Statistics; 20 I2. Available from: http://www.surgery.org/ sites/default?files/2012stats.pdf. [Last accessed on 2014 Sep I0].

3. Bostwick J. Prophylactic (risk-reducing) mastectomy and reconstruction. Plastic and Reconstructive Breast Surgery. Vol. II. St. Louis: Quality Medical Publishing; 1990. p. 1369-73.

4. King IC, Harvey JR, Bhaskar P. One-stage breast reconstruction using the inferior dermal flap, implant, and free nipple graft. Aesthetic Plast Surg 2014;38:358-64.

5. Forcada EM, Fernández MC, Aso JV, Iglesias IP. Augmentation mastopexy: maximal reduction and stable implant coverage using four flaps. Aesthetic Plast Surg 2014;38:7II-7.

6. Coleman SR, Saboeiro AP. Fat grafting to the breast revisited: safety and efficacy. Plast Reconstr Surg 2007; I 19:775-85.

7. Khan UD.Aesthetic surgery of the breast. In:Mugea TT,Shiffman MA, editor. Use of nipple-areolar to inframammary crease mesurments to reduce bottoming out following augmentation mastopexy. Berlin: Springer; 20I5. p. 649-56.

8. Ladizinsky DA, Sandholm PH, Jewett ST, Shahzad F, Khalil A. Breast reconstruction with Botswick autoderm technique. Plast Reconstr Surg 2013;|32:26|-70.

How to cite this article: Khan UD. Inferior dermoglandular flap for autologous breast remodeling following explantation of breast implants in ptotic breasts: a case report and literature search. Plast Aesthet Res 2015;2:81-4.

Source of Support: Nil, Conflict of Interest: None declared.

Received: 11-11-2014; Accepted: 22-12-2014 